\title{
Wasp mimicry among Palaeocene reduviid bug from Svalbard
}

Torsten Wappler, Romain Garrouste, Michael S. Engel, and André Nel

Acta Palaeontologica Polonica 58 (4), 2013: 883-887 doi: http://dx.doi.org/10.4202/app.2011.0202

The enigmatic Svalbard Palaeocene fossil taxon Hymenopterites deperditus is revised, and is neither a wasp nor a plant seed, but turns out to be a bug hemelytra corresponding to the oldest described reduviid bug. It can be attributable to the "emesine-saicine clade". The presence in the Svalbard Palaeocene of this insectivorous bug, showing possible mimicry of a wasp model, confirms the presence of diverse entomofauna and of rather warm palaeoclimatic conditions.

Torsten Wappler [twappler@uni-bonn.de], Steinmann-Institut für Geologie, Mineralogie und Paläontologie, Universität Bonn, Nußallee 8, D-53115 Bonn, Germany; Romain Garrouste [garroust@mnhn.fr] and André Nel [anel@mnhn.fr], CNRS UMR 7205, Muséum National d'Histoire Naturelle, CP 50, Entomologie, 45 rue Buffon, F-75005 Paris, France; Michael S. Engel [msengel@ks.edu], Division of Entomology, Natural History Museum, and Department of Ecology \& Evolutionary Biology, 1501 Crestline Drive - Suite 140, University of Kansas, Lawrence, Kansas 66049-2811, USA.

This is an open-access article distributed under the terms of the Creative Commons Attribution License (for details please see creativecommons.org), which permits unrestricted use, distribution, and reproduction in any medium, provided the original author and source are credited. 